\title{
THE FATTY ACID PATTERNS OF PLASMA LIPIDS DURING ALIMENTARY LIPEMIA *
}

\author{
By V. P. DOLE, A. T. JAMES, J. P. W. WEBB, M. A. RIZACK ANd M. F. STURMAN $\dagger$ \\ (From The Rockefeller Institute, New York, N. Y., and the National Institute for Medical \\ Research, London, England)
}

(Submitted for publication March 11, 1959; accepted April 23, 1959)

The total amount of fatty acid contained in the blood stream at any moment is considerably less than the amount of fat that might be taken in a single feeding. Therefore, during the period of alimentary lipemia some of the lipids in blood would be expected to acquire the composition of dietary fat.

To illustrate, the blood plasma of a $70 \mathrm{Kg}$. man contains about $50 \mathrm{mEq}$. of fatty acids (approximately $25 \mathrm{mEq}$. in phospholipids, $12 \mathrm{mEq}$. in cholesterol esters, $10 \mathrm{mEq}$. in triglycerides and $3 \mathrm{mEq}$. in nonesterified fatty acids), whereas a meal containing 3 ounces of fat provides $300 \mathrm{mEq}$. The amount of fatty acid entering the blood during a period of a few hours after such a feeding thus is about six times the total amount in circulation and, since the concentration of fatty acid in plasma remains approximately constant during absorption, the fatty acids of plasma must turn over on the average about six times. The actual turnover of transport lipids must be much greater than this since only a small part of the plasma lipid participates directly in absorption. Practically all of the newly absorbed fat enters the blood as triglyceride $(1,2)$. If dietary fat were simply mixed with this small pool and then transported to the tissues, the pool would turn over about 30 times and the composition of plasma triglyceride would become identical with that of dietary fat during the period of absorption.

Some evidence of this expected effect was obtained by Wilson and Hanner (3) who fed large doses of cream or cod liver oil to children and observed that the iodine number of the increment of blood lipids during the lipemic phase became approximately equal to the iodine number of the fed fat. It is also known that the composition of

* This research was supported in part by Grant A-2427 from the National Institutes of Health, United States Public Health Service, Bethesda, Md.

$\uparrow$ Fellow of the Dazian Foundation for Medical Research. adipose tissue in various animals (4) and man (5) can be changed by feeding diets containing large amounts of unsaturated acids; therefore, there can be little doubt that the blood stream must transport a substantial part of the dietary fatty acid from gut to depot without modification.

On the other hand, a number of studies in the older literature [reviewed by Bloor (6)] showed that the iodine number and melting point of fat in thoracic duct lymph can differ significantly from the corresponding values for the fat that had been fed, and therefore that the fat delivered into the blood need not have the same fatty acid pattern as the dietary mixture. More recently Fernandes, Van de Kamer and Weijers (7) in studying a child with chylothorax found that the pattern of fatty acids in the chyle was influenced by the kind of fat fed during the preceding week, but significant differences between chyle and dietary fat always remained.

In the present study it was found that absorption of $100 \mathrm{Gm}$. of corn oil, coconut oil or butter caused remarkably little change in the fatty acid patterns of chylomicra in plasma or in the patterns of other plasma fractions. These results and the results of other studies of the absorptive process must be distinguished clearly from the effects of feeding some distinctive fat over a period of many weeks (8-11). In the present case one is concerned with a transport process; in the latter, with a slow change in composition of tissue lipids caused by repeated feedings and the manifestation of this change in the plasma of fasting subjects.

\section{METHODS}

Chylomicra were separated from plasma by flotation into a supernatant layer of saline $(100,000 \mathrm{G} \times 30 \mathrm{~min}$ utes) (12).

Nonesterified fatty acids were extracted into heptane with the heptane-acid-isopropyl alcohol system previously described (13) and then were transferred into 90 per cent ethanol-water by titration of a two-phase heptane 
extract, ethanol-water system with $0.02 \mathrm{~N} \mathrm{NaOH}$. After extraction of the alkaline ethanol-water phase with petroleum ether to remove contaminating esters, the nonesterified fatty acids were methylated for chromatography.

Plasma lipids were extracted with ether-ethanol; the extract was evaporated to dryness and the cholesterol ester plus triglyceride fraction separated from the phospholipids by extraction of the residue with acetone. The esterified fatty acids were saponified in 10 per cent methanolic $\mathrm{KOH}$, extracted after removal of nonsaponifiable material and methylated with methanolic $\mathrm{HCl}$.

The methyl esters were stored as solutions in petroleum ether (B. P., 40 to $60^{\circ}$ C.) in the cold until analyzed. Separations were carried out using two types of stationary phase: a) Apiezon $\mathrm{L}$ vacuum stopcock grease at $197^{\circ} \mathrm{C}$. (14) ; and $b$ ) a polymer of ethylene glycol and adipic acid at $175^{\circ} \mathrm{C}$. (15-17). In the earlier work, the gasdensity balance (18) was used as the vapor detector, total loads of ester separated being approximately $3 \mathrm{mg}$. At this level of sensitivity large samples of plasma were required ( 50 to $75 \mathrm{ml}$.) particularly when dealing with the nonesterified fatty acid fractions. The introduction of the much more sensitive argon ionization detector $(19,20)$ allowed a total column load of $100 \mu \mathrm{g}$. or less to be used, so that more detailed physiological studies were possible with much smaller blood samples. Peak areas were measured by triangulation and analyses were usually carried out at two or more levels in order to determine major and minor components accurately. The analytical figures given refer to percentage by weight of a given component in the acids of chain length $\mathrm{C}_{6}$ and $\mathrm{C}_{20}$.

The course of lipemia in some experiments was followed by determination of triglyceride by the method of Van Handel and Zilversmit (21).

\section{EXPERIMENTAL PROCEDURE}

For control data samples of plasma were obtained from two groups of human subjects: male medical students and a somewhat older group of male and female laboratory personnel. All subjects appeared healthy and of usual dietary habits. At the time of testing all subjects were at least 12 hours post prandial. The analyses of animal plasma fractions were made on specimens obtained from fasting animals maintained on commercial feeds.

Fasting male medical students from the blood donor list served as subjects for the feeding experiments. After an initial sample of blood had been taken, each subject was fed $100 \mathrm{Gm}$. of test fat (corn oil, coconut oil or butter) with no other food. Thereafter they were bled three times : at one-half, one, and two and one-half hours (shortterm studies) or at three, six and nine hours (longer term). During the period of observation the subjects remained ambulatory and were permitted water, ad libitum, but nothing else by mouth.

Blood was taken into heparinized flasks and centrifuged promptly to remove cells. Because of the relatively low sensitivity of the chromatographic detector available in 1957 it was necessary to take about $100 \mathrm{ml}$. of blood in each sample. The more recent analyses have required only $10 \mathrm{ml}$. of blood. Fortunately these later studies have given essentially the same results as the earlier experiments, which suggests that removal of 300 to $400 \mathrm{ml}$. of blood does not distort the fatty acid patterns, and so the data from the earlier and the more recent experiments are considered together.

\section{TREATMENT OF THE DATA}

The wide variety of fatty acids now shown to occur in animal fats makes the familiar terminology inadequate and the systematic chemical nomenclature too cumbersome for tabulation of analytical results. We have found it convenient to identify fatty acids by a dual symbol: the first figure denoting chain length, and the second, the number of double bonds (e.g., 16:0 for palmitic acid, 18:1 for oleic acid and 18:2 for linoleic acid). The symbol can be elaborated further to show whether the chain is branched or straight (e.g., branched 15:0) and. positional isomers can be distinguished by suffixes (e.g., $\left.18: 1^{1-10}\right)$. However, even with this simplified tabulatio a it is difficult to compare mixtures having the same maj( )r but different minor components. We have explored t'he possibility of using statistical methods for measuring 1 he similarity of different patterns but the calculations have not been helpful to date because the relative import? nnce of different components is not yet defined.

The "double bond index" (DBI) shown in the tables is a measure of unsaturation, calculated from the for mula, $\mathrm{DBI}=\Sigma\left(\mathrm{n}_{1} \mathrm{w}_{1} / \mathrm{m}_{1}\right) \quad$ (where $n_{1}$ is the number of 'jouble bonds in the fatty acid $i, m_{1}$ is the molecular weig, ht and $w_{i}$ the percentage by weight of the fatty acid in the given mixture). The factors $n_{1} / m_{1}$, given in Table $I$, were multiplied by the corresponding percentages obtained from the analysis and the products were summed to give the number of double bonds per unit weight of nixed fatty acids.

\section{RESULTS}

\section{Fasting subjects}

Tables II and III give the fatty acid composition of the various plasma lipids isolated from both humans and animals. The category " $18: 1$ isomers" refers to isomers of oleic acid that consist mainly of trans- 11:12 -octadecanoic acid (vaccenic) (22); 20:3 refers to an acid whose structure has been partially elucidated by degradation; and 18-22:? refers to a group of unsaturated acids whose structure has yet to be determined.

\section{Short experiments}

Table IV shows the compositions of the three different dietary fats and the fatty acid patterns of nonesterified fatty acids before and up to two and one-half hours after the feedings, each datum 
TABLE I

Numerical factors for calculation of double bond index (DBI)

\begin{tabular}{ccccccccc}
\hline \hline Acid & $12: 1$ & $14: 1$ & $16: 1$ & $18: 1$ & $18: 2$ & $18: 3$ & $20: ?$ \\
$\frac{\mathrm{n}_{\mathrm{i}}}{\mathrm{m}_{\mathrm{i}}}$ & 0.505 & 0.442 & 0.394 & 0.354 & 0.714 & 1.080 & 1.315 & \\
\hline
\end{tabular}

in the table being the average of two tests with different subjects. There was essentially no change in the patterns except for a rise in lauric $(12: 0)$ and myristic $(14: 0)$ acids after ingestion of coconut oil. Statistical analyses verified the significance of these rises and also indicated that none of the other variations in pattern (including fluctuations in trace components not shown in the table) had any significant relation to the pattern of dietary load. The double bond indices (which measure net unsaturation) remained essentially constant.

\section{Longer experiments}

The experiments running up to nine hours did show a number of significant changes (Tables $\mathrm{V}$ and VI), but of relatively minor degree. For instance, the chief components of corn oil feedings, the unsaturated $\mathrm{C}_{18}$ acids, comprised 89 per cent of the total load [oleic $(18: 1)$ and its isomers accounted for 34 per cent, and linoleic (18:2) for about 55 per cent], yet during absorption, the proportion of $18: 2$ in each plasma fraction rose only moderately, remaining well below the dietary

TABLE II

Composition of plasma lipids in human subjects*

\begin{tabular}{|c|c|c|c|c|}
\hline Component & NEFA $\dagger$ & Chylomicra & Phospholipid & $\begin{array}{l}\text { Triglycerides-plus- } \\
\text { cholesterol-esters }\end{array}$ \\
\hline No. of subjects & 18 & 6 & 6 & 6 \\
\hline \multicolumn{5}{|l|}{ Saturated } \\
\hline $\begin{array}{l}12: 0 \\
14: 0 \\
15: 0 \\
16: 0 \\
17: 0 \\
18: 0 \\
20: 0\end{array}$ & $\begin{array}{r}0.3 \pm 0.4 \\
1.7 \pm 0.9 \\
23.2 \pm 2.8 \\
12.9 \pm 2.6\end{array}$ & $\begin{array}{r}1.9 \pm 1.5 \\
3.7 \pm 1.4 \\
0.8 \pm 0.8 \\
24.2 \pm 4.7 \\
0.4 \pm 0.4 \\
10.4 \pm 1.7\end{array}$ & $\begin{array}{r}0.1 \pm 0.1 \\
1.1 \pm 0.8 \\
0.5 \pm 0.5 \\
33.1 \pm 3.8 \\
0.5 \pm 0.5 \\
12.8 \pm 3.3 \\
0.3 \pm 0.4\end{array}$ & $\begin{aligned} 0 & \pm 0 \\
1.0 & \pm 0.4 \\
0.2 & \pm 0.2 \\
21.4 & \pm 2.2 \\
0.5 & \pm 0.3 \\
4.2 & \pm 1.2\end{aligned}$ \\
\hline \multicolumn{5}{|l|}{ Tonounsaturated } \\
\hline \multirow{2}{*}{$\begin{array}{l}12: 1 \\
14: 1 \\
6: 1 \\
3: 1^{9-10} \\
1: 1^{\text {isomors }}\end{array}$} & \multirow{2}{*}{$\left.\begin{array}{r}0.6 \pm 1.0 \\
2.4 \pm 0.9 \\
28.9 \pm 5.0 \\
3.7 \pm 1.3\end{array}\right\}$} & $\begin{array}{l}0.9 \pm 1.0 \\
1.4 \pm 1.0 \\
3.0 \pm 1.0\end{array}$ & $\begin{array}{l}0.4 \pm 0.1 \\
0.5 \pm 0.5 \\
2.5 \pm 0.7\end{array}$ & $\begin{array}{r}0 \pm 0.1 \\
0.4 \pm 0.3 \\
3.4 \pm 1.0\end{array}$ \\
\hline & & $21.8 \pm 4.8$ & $18.6 \pm 4.7$ & $26.4 \pm 5.5$ \\
\hline \multicolumn{5}{|l|}{ Diu } \\
\hline $18 ?$ & $14.5 \pm 4.1$ & $8.7 \pm 1.2$ & $16.0 \pm 6.5$ & $33.5 \pm 5.5$ \\
\hline \multicolumn{5}{|l|}{ Polyu isaturated } \\
\hline $\begin{array}{l}18: 3 \\
20: 3 \\
20: 4 \\
18 \rightarrow 22: ?\end{array}$ & $\begin{array}{l}1.3 \pm 1.5 \\
4.7 \pm 2.6\end{array}$ & $\begin{array}{l}0.3 \pm 0.3 \\
2.0 \pm 2.0 \\
0.5 \pm 0.5 \\
8.0 \pm 8.0\end{array}$ & $\begin{array}{l}0.5 \pm 0.6 \\
1.8 \pm 0.6 \\
4.3 \pm 2.1 \\
4.1 \pm 4.0\end{array}$ & $\begin{array}{l}0.5 \pm 0.5 \\
1.0 \pm 0.5 \\
4.2 \pm 2.0 \\
2.0 \pm 2.0\end{array}$ \\
\hline Sum & 94.2 & 88.0 & 97.1 & 98.7 \\
\hline Double bond index & $28.0 \pm 5.7$ & $32.5 \pm 11.4$ & $33.3 \pm 3.5$ & $44.1 \pm 2.8$ \\
\hline
\end{tabular}

* Values given in the main part of the table are the mean and standard deviation of percentage by weight for each component. The sum is less than 100 per cent in each case because inconstant trace amounts of unusual acids, detected in individual analyses, were omitted from the final tabulations. The double bond index, defined in the text, measures degree of unsaturation.

t Nonesterified fatty acids. 
PLASMA FATTY ACIDS DURING ALIMENTARY LIPEMIA

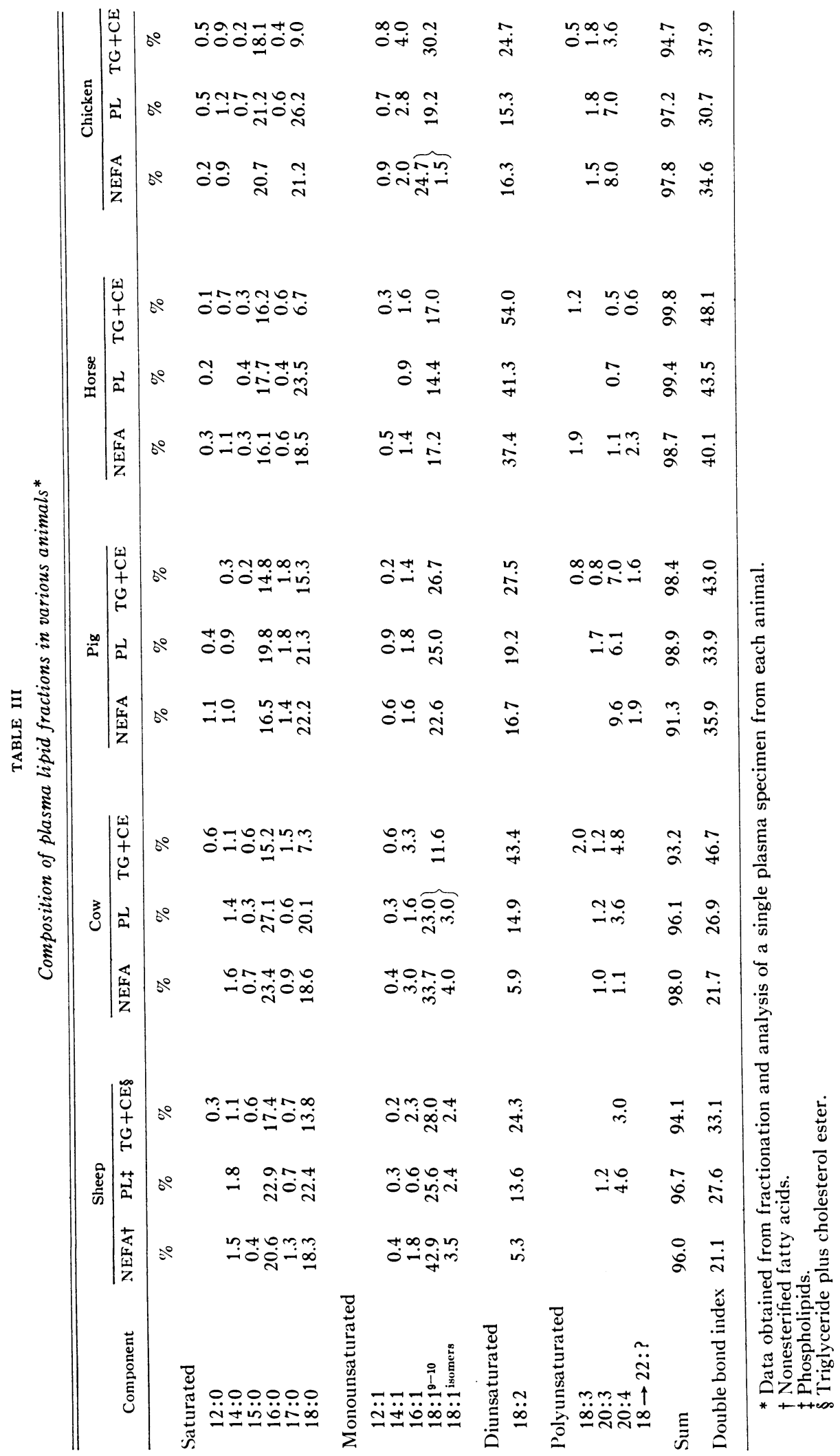


DOLE, JAMES, WEBB, RIZACK AND STURMAN

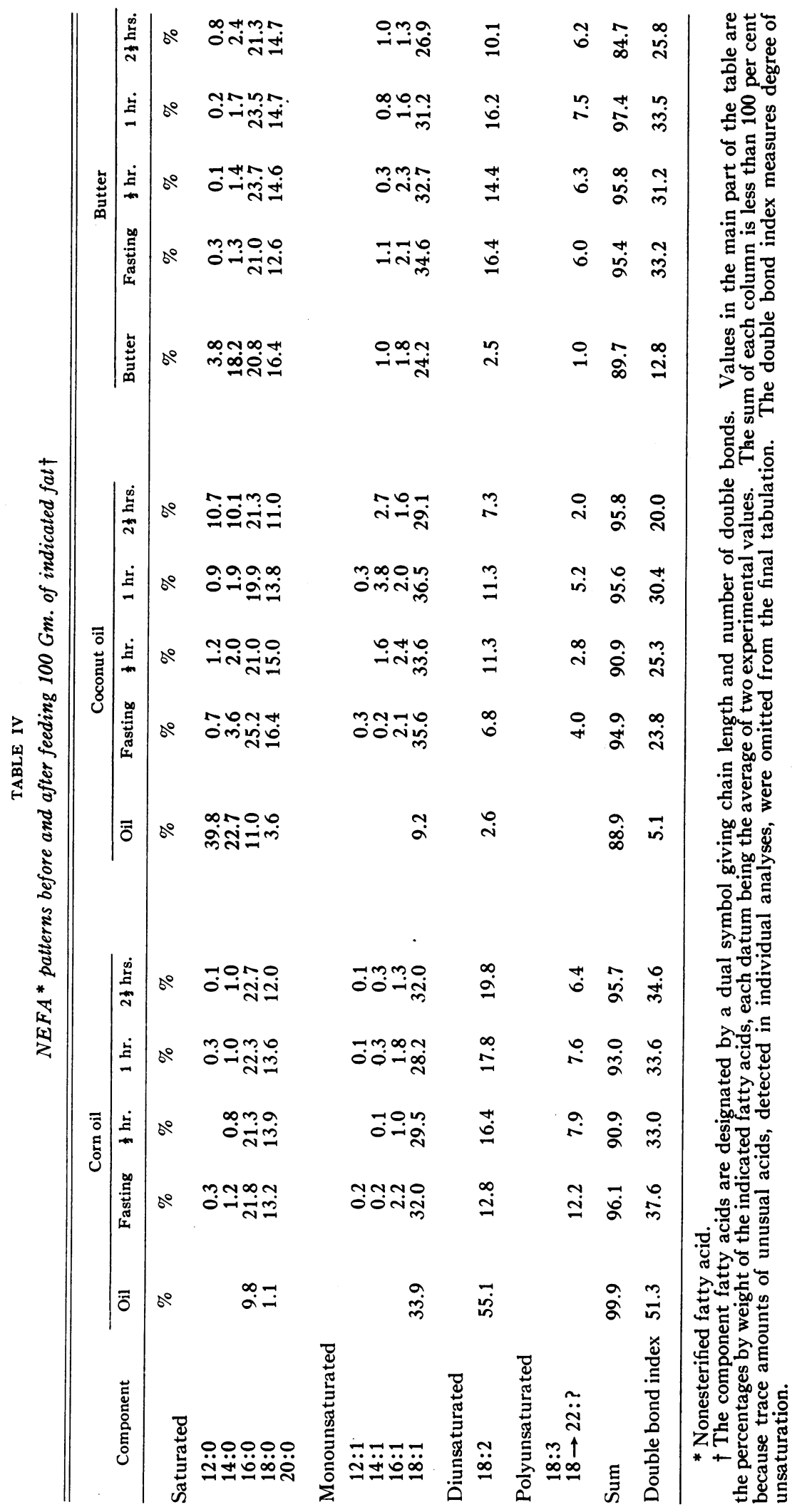


PLASMA FATTY ACIDS DURING ALIMENTARY LIPEMIA

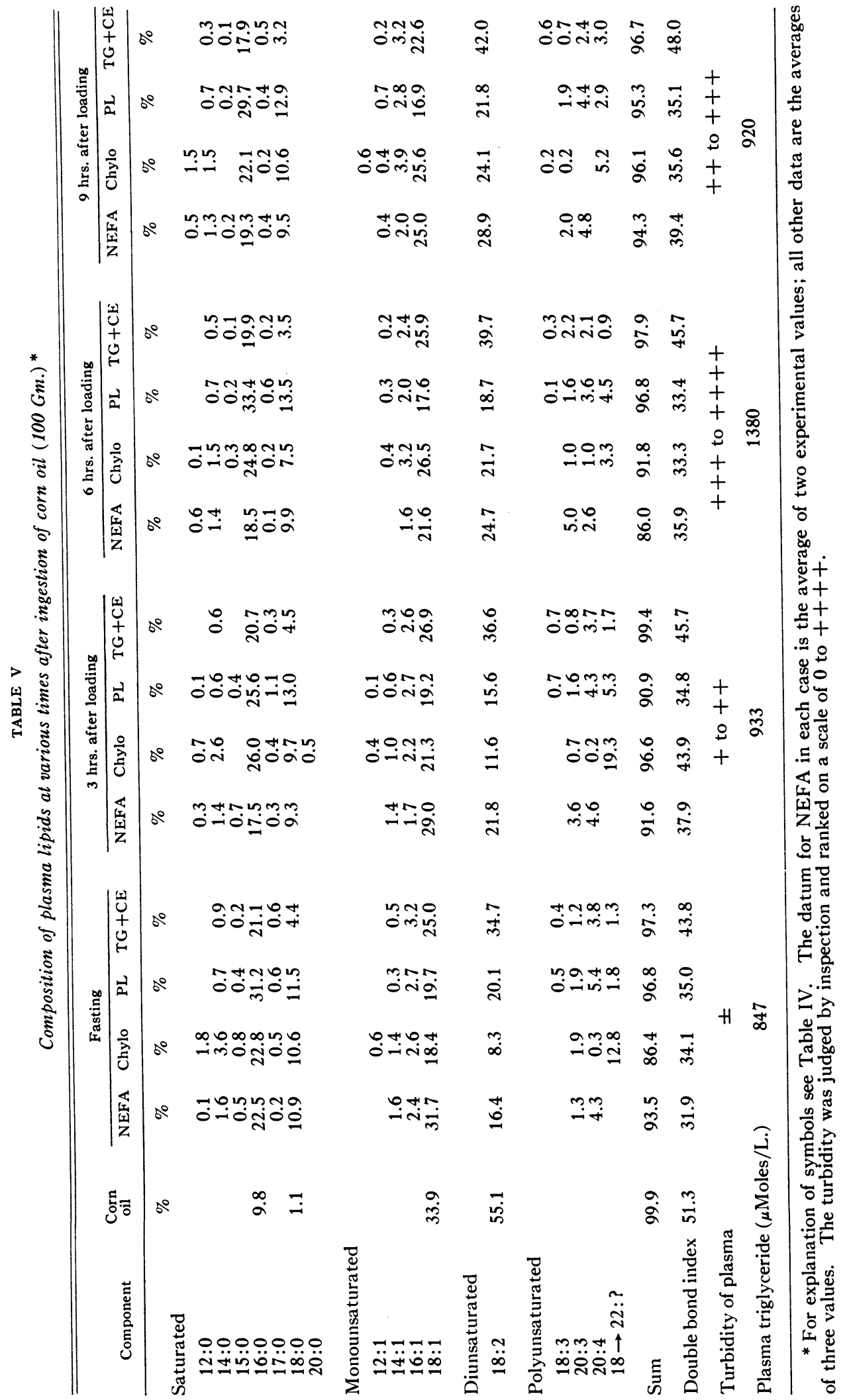


DOLE, JAMES, WEBB, RIZACK AND STURMAN

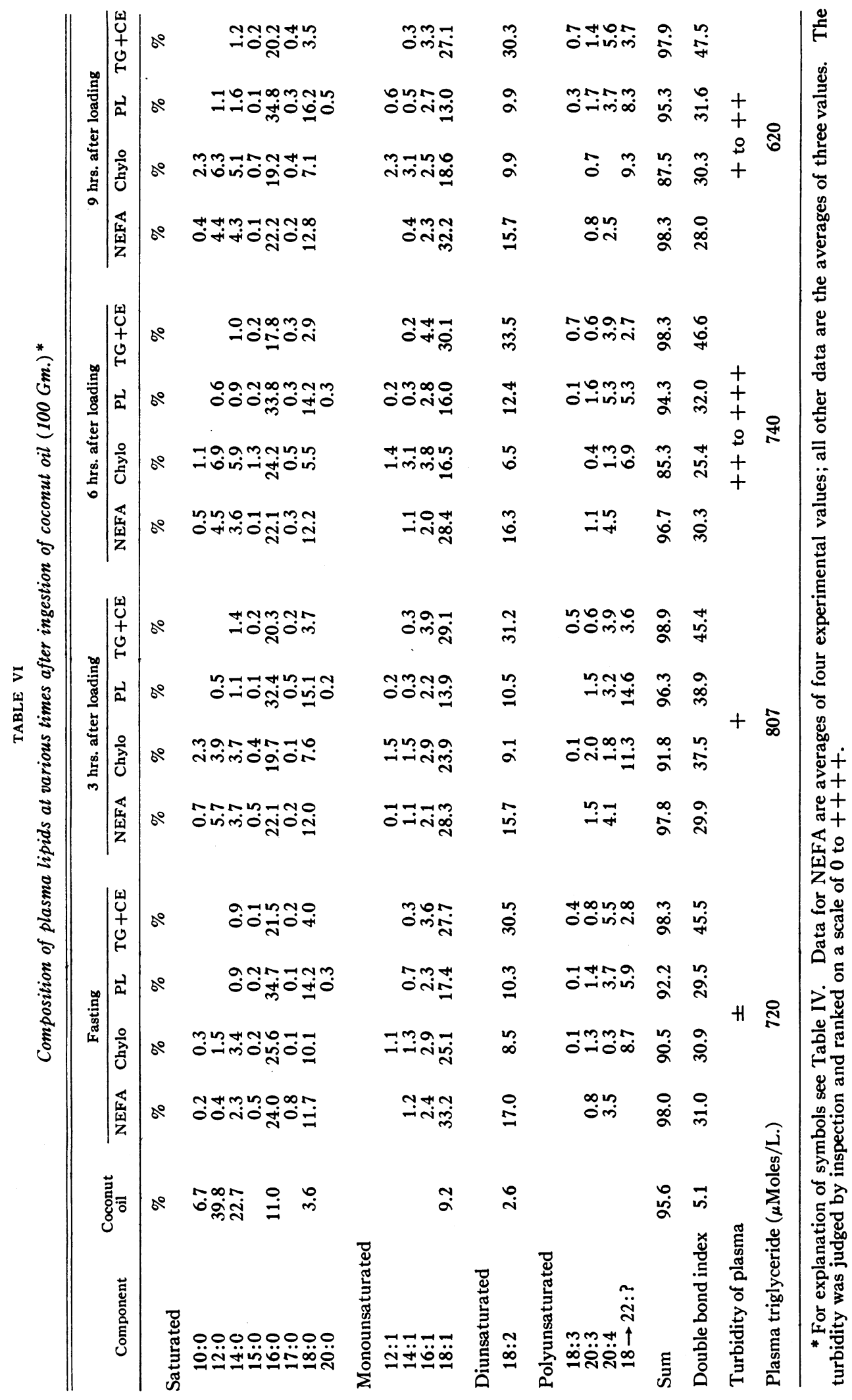


level, while 18:1 remained constant or fell so that the total $\mathrm{C}_{18}$ concentration remained essentially unchanged and the double bond index showed no consistent trend.

The stability of the patterns is illustrated in Figures 1 through 4, which show the fatty acid distributions classified by saturation and chain length. It will be seen in Figure 1 that chylomicra tended to maintain the pattern found in fasting samples, although the effect of the dietary load was perceptible. The pattern during absorption, considered as a mixture between dietary fat and the body lipids with the fasting pattern, suggests that dietary fat contributed at most only half of the oleic acid present in chylomicra (based on the elevation of $18: 2$ ) and, with respect to other components, a much smaller proportion.

The nonesterified fatty acids (Figure 2 ) also responded perceptibly to the dietary load, while

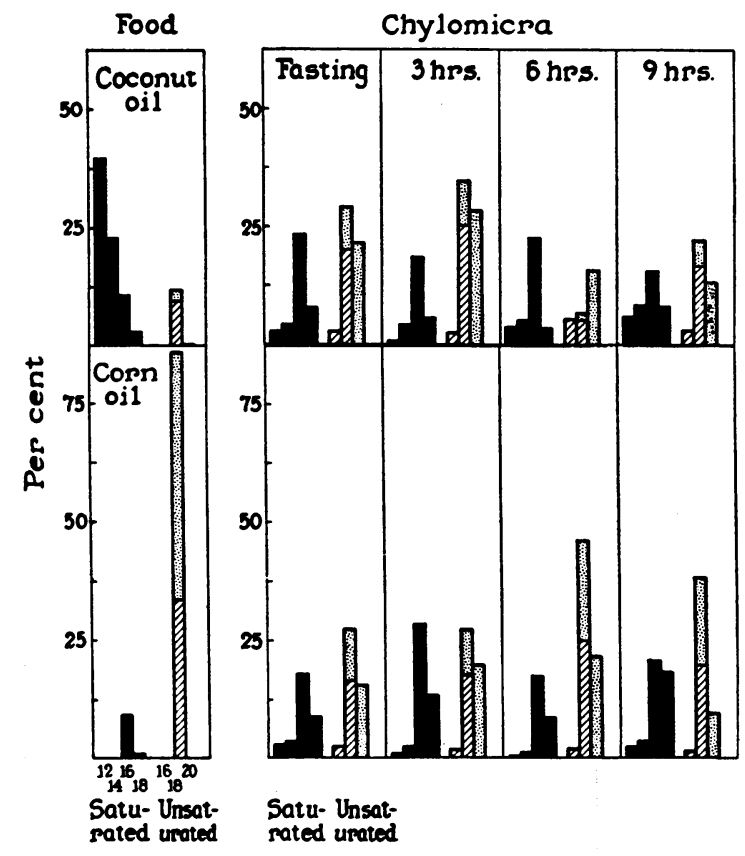

Fig. 1. Patterns of Fatty Acids in Chylomicra After Feeding $100 \mathrm{Gm}$. of Coconut OIL (Upper Row) OR CORN OIL (LOWER Row)

The composition of dietary fat is shown on the left, followed by chylomicron patterns in blood samples obtained before feeding and at the indicated times subsequently. Saturated fatty acids are shown in solid black; monounsaturated acids are shown with crosshatching, and polyunsaturated, with stippling. The chain lengths, shown under the corn oil diagram, apply similarly to each of the other diagrams.
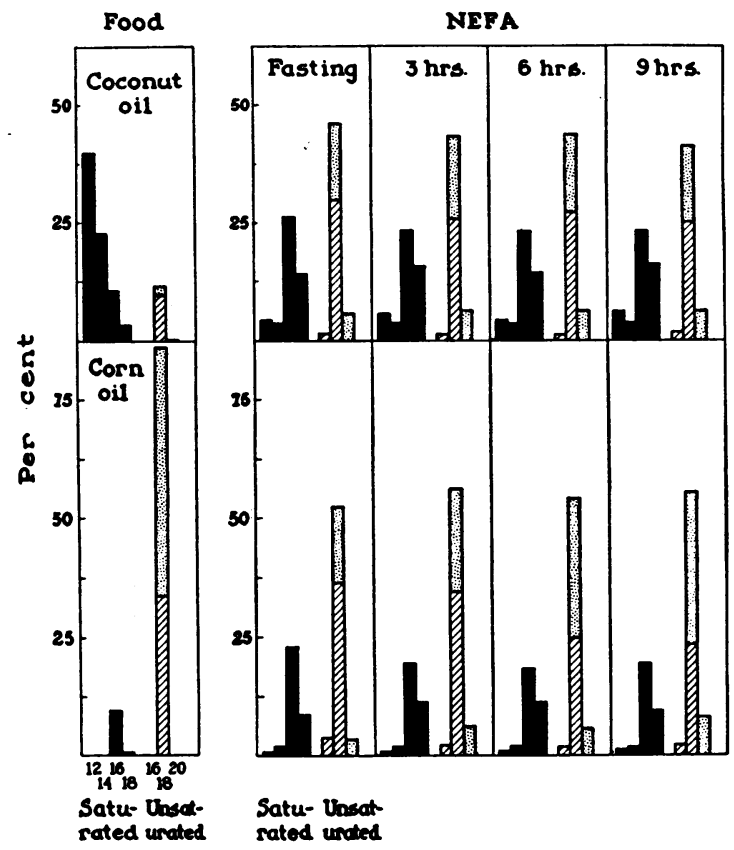

Fig. 2. Nonesterified fatty acid (NEFA)

the patterns of triglyceride plus cholesterol esters (Figure 3) and phospholipids (Figure 4) were virtually unchanged.

\section{DISCUSSION}

\section{Fasting subjects}

As has been noted before (23), each class of lipid was found to have a distinctive composition with a relatively small spread of values for major and minor components within each class (Table II).

The high concentration of polyunsaturated acids found in chylomicra is of particular interest since chylomicra are known to contain less than 10 per cent of phospholipids $(24,25)$. It would seem, therefore, that either part of the triglyceride in chylomicra was highly unsaturated or the phospholipid component contained an exceptionally large amount of unsaturated acids. In either case some of the chylomicron lipid must have been derived from an endogenous source rich in polyunsaturated acids. In addition the chylomicra contained less linoleic acid than the other fractions.

Some of the present data can be compared with those obtained in a previous study of British subjects (23). The phospholipid composition is 


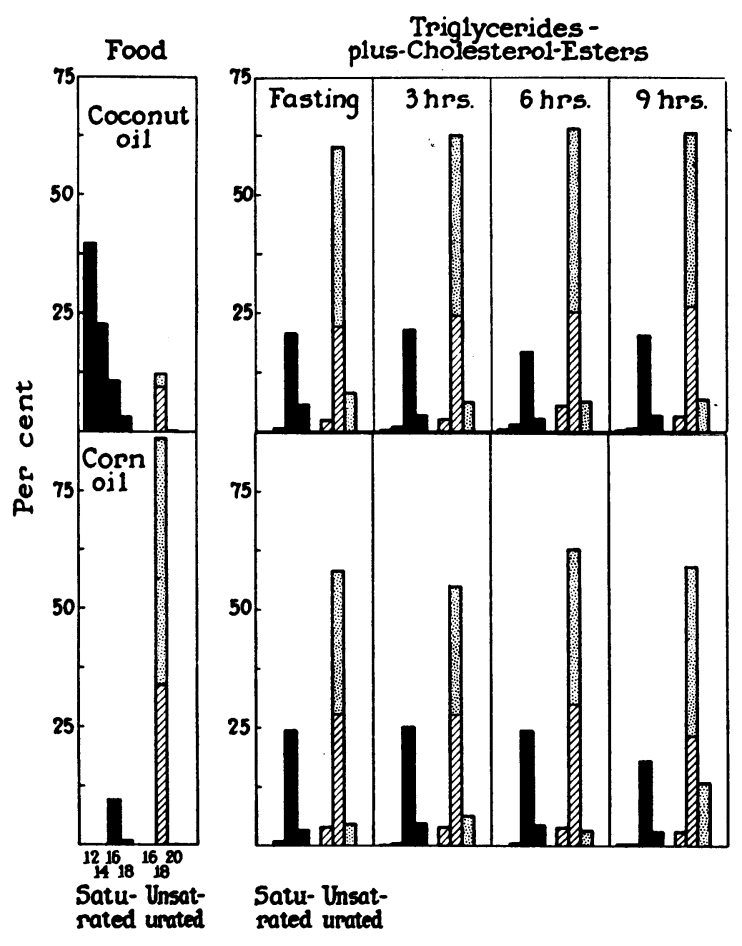

Fig. 3. TRIGLycerides PlUS ChOLESTERol esters

similar in the two groups except that palmitic acid appears to be somewhat higher in the Amierican group and arachidonic acid, lower. Larger differences are seen in the cholesterol ester plus triglyceride fraction; the American group had a much higher linoleic level $(33.5 \pm 5.5$ per cent) than the British (12.4 per cent), while the British group showed a somewhat higher oleic acid level (34.7 per cent) than the Americans (26.4 \pm 5.5 per cent). Presumably these differences were due to higher cholesterol/triglyceride ratios in the American subjects.

Table III shows the fatty acid compositions of nonesterified fatty acids, phospholipds and cholesterol esters plus triglyceride in plasma of sheep cow, pig, horse and chicken. The three lipid fractions appeared to have fairly consistent patterns in all the animals studied; this similarity is in striking contrast to the wide differences in kind of food eaten by the various species.

\section{Lipemia}

The degree of alimentary lipemia depends both on the kind of fat fed (26) and on the dose. Moderate loads, such as might be eaten in a normal meal, usually cause little or no rise in total lipid concentration of plasma (27) although they are reflected in chylomicronemia and turbidity during the period of absorption (28). To obtain a substantial rise in concentration of plasma fatty acids one must feed a large amount of fat, such as 3.5 $\mathrm{Gm}$. per $\mathrm{Kg}$. (29). In the experiment of Wilson and Hanner (3) children were fed even larger doses, up to $5.6 \mathrm{Gm}$. per $\mathrm{Kg}$. Changes in plasma fatty acid pattern did occur under these conditions, but in interpreting the results one must note the unphysiological size of the load.

With the more moderate feedings used in the present experiments, the subjects in the corn oil group showed a slight rise in plasma triglyceride concentration while those in the coconut oil group showed no significant change; all subjects, however, showed definite turbidity of plasma during absorption, usually maximal at six hours. Centrifugation of the turbid plasma under a layer of saline in each case yielded a creamy chylomicron layer and this, as is indicated in the tables, had a fatty acid composition quite different from the fed fat.

In interpreting the constancy of the fatty acid pattern of chylomicra it must be recognized that some of the fatty acids in chylomicra are contained in phospholipids and cholesterol esters (and so are not necessarily related to the dietary

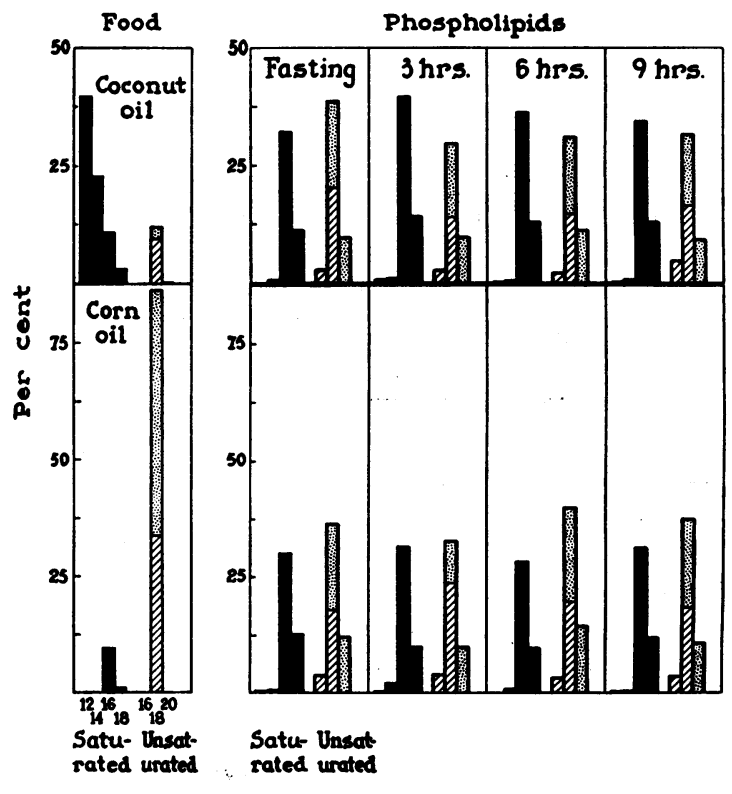

Fig. 4. Рноspholipids 
load), and also that the flotation layer obtained from the upper part of the saline phase might be contaminated with nonchylomicron lipids. These explanations, however, fail to account for the discrepancy between chylomicra and fed fat. It is unlikely that the phospholipids and cholesterol esters in chylomicra could have contributed more than 10 per cent of the fatty acids $(24,25)$ and the composition of the chylomicron fraction was very far from what one would obtain by a mixture of nine parts of dietary fat with one part of phospholipid or any other fraction of the subnatant plasma. It also seems unlikely that any contamination of the flotation layer with nonchylomicron lipids could have been great enough to predominate over the chylomicron lipids; centrifugation of plasma from fasting subjects yielded only traces of lipids, while at the peak of lipemia, the same procedure yielded a heavy cream. Finally, the constancy in composition of the triglyceride plus cholesterol ester fraction showed that there could not have been any appreciable proportion of unmodified dietary triglyceride in this fraction (which includes chylomicron triglyceride) at the time of any observation.

Two different kinds of process might account for the relative stability of the various plasma fatty acid patterns during absorption. There might be, as Bloor suggested (6), a conversion of fatty acids during digestion. Alternatively, the fatty acid patterns of plasma lipids, including chylomicra, might be held constant by rapid recycling of fatty acids between blood and tissue pools, as is the case with nonesterified fatty acids $(12,30)$. Work now in progress in this laboratory indicates that the latter alternative is the correct one.

It is also of interest to note that the nonesterified fatty acid pattern did not follow changes in the chylomicron pattern as might be expected if the clearing of lipemia plasma were simply lipolytic and the nonesterified fatty acids were products. This result is in agreement with the experiments of Fredrickson, McCollester and Ono (31) who showed that not more than one molecule in 10 of the nonesterified fatty acids was derived from labeled chylomicra when these were infused into dogs at rates comparable to that of normal absorption.

\section{SUMMARY}

Plasma lipids were fractionated into chylomicra, nonesterified fatty acids, triglycerides plus cholesterol esters and phospholipids, and the fatty acid compositions of these fractions were determined by analysis with gas-liquid chromatography. The data showed a fairly consistent pattern for each fraction in a group of normal fasting subjects. A few analyses made on animal plasmas yielded essentially the same patterns.

Plasmas taken during alimentary lipemia were analyzed similarly. It was found that neither the chylomicra, nor any other fraction, acquired the pattern of dietary fat during the period of lipemia. This result suggests that the fatty acid pattern of chylomicra in plasma is stabilized by equilibration with a larger pool of tissue lipids.

\section{REFERENCES}

1. Bloom, B., Chaikoff, I. L., and Reinhardt, W. O. Intestinal lymph as pathway for transport of absorbed fatty acids of different chain lengths. Amer. J. Physiol. 1951, 166, 451.

2. Bergström, S., Blomstrand, R., and Borgström, B. Route of absorption and distribution of oleic acid and triolein in the rat. Biochem. J. 1954, 58, 600.

3. Wilson, W. R., and Hanner, J. P. Changes of total lipid and iodine number of blood fat in alimentary lipemia. J. biol. Chem. 1934, 106, 323.

4. Hilditch, T. P. The Chemical Constitution of $\mathrm{Na}$ tural Fats, 3rd ed. New York, John Wiley and Sons, Inc., 1956, p. 475.

5. Hirsch, J., Farquhar, J. W., Peterson, M. L., and Stoffel, W. The fatty acid composition of adipose tissue in man (abstract). J. clin. Invest. 1959, 38, 1011.

6. Bloor, W. R. On fat absorption. III. Changes in fat during absorption. J. biol. Chem. 1913-14, 16, 517.

7. Fernandes, J., Van de Kamer, J. H., and Weijers, H. A. The absorption of fats studied in a child with chylothorax. J. clin. Invest. 1955, 34, 1026.

8. Kinsell, L. W. Effects of high-fat diets on serum lipids; animal vs. vegetable fats. J. Amer. diet. Ass. 1954, 30, 685.

9. Ahrens, E. H., Jr., Blankenhorn, D. H., and Tsaltas, T. T. Effect on human serum lipids of substituting plant for animal fat in diet. Proc. Soc. exp. Biol. (N. Y.) 1954, 86, 872.

10. Bronte-Stewart, B., Antonis, A., Eales, L., and Brock, J. F. Effects of feeding different fats on serum-cholesterol level. Lancet 1956, 1, 521.

11. Holman, R. T., Hayes, H., Malmros, H., and Wigand, G. Effects of dietary fat upon plasma polyunsaturated acids. Proc. Soc. exp. Biol. (N. Y.) 1957, 96, 705 . 
12. Fredrickson, D. S., McCollester, D. L., Havel, R. J., and Ono, $\mathrm{K}$. The early steps in transport and metabolism of exogenous triglyceride and cholesterol in The Chemistry of Lipids as Related to Atherosclerosis, I. H. Page, Ed. Springfield, IIlinois, Charles C Thomas, 1958, p. 205.

13. Dole, V. P. A relation between non-esterified fatty acids in plasma and the metabolism of glucose. J. clin. Invest. 1956, 35, 150.

14. James, A. T., and Martin, A. J. P. Gas-liquid chromatography: The separation and identification of the methyl esters of saturated and unsaturated acids from formic acid to $n$-Octadecanoic acid. Biochem. J. 1952, 63, 144.

15. Orr, C. H., and Callen, J. E. Separation of polyunsaturated fatty acid methyl esters by gas chromatography. J. Amer. chem. Soc. 1958, 80, 249.

16. Lipsky, S. R., and Landowne, R. A. A new partition agent for use in the rapid separation of fatty acid esters by gas-liquid chromatography. Biochim. biophys. Acta 1958, 27, 666.

17. James, A. T. The separation of the long chain fatty acids by gas-liquid chromatography. Amer. J. clin. Nutr. 1958, 6, 595.

18. Martin, A. J. P., and James, A. T. Gas-liquid chromatography: The gas density meter, a new apparatus for the direction of vapours in flowing gas streams. Biochem. J. 1956, 63, 138.

19. Lovelock, J. E. A sensitive detector for gas chromatography. J. Chromat. 1958, 1, 35.

20. Lovelock, J. E., James, A. T., and Piper, E. A. A new type of ionization detector for gas chromatography. Ann. N. Y. Acad. Sci. 1959, 72, 720.

21. Van Handel, E., and Zilversmit, D. B. Micromethod for the direct determination of serum triglycerides. J. Lab. clin. Med. 1957, 50, 152.
22. James, A. T., and Webb, J. The determination of the structure of unsaturated fatty acids on a micro scale with the gas-liquid chromatogram. Biochem. J. 19.57, 66, 515.

23. James, A. T., Lovelock, J. E., Webb, J., and Trotter, W. R. The fatty acids of the blood in coronaryartery disease. Lancet 1957, 1, 705.

24. Bragdon, J. H., Havel, R. J., and Boyle, E. Human serum lipoproteins. I. Chemical composition of four fractions. J. Lab. clin. Med. 1956, 48, 36.

25. Hillyard, L. A., Chaikoff, I. L., Entenman, C., and Reinhardt, W. O. Composition and concentration of lymph and serum lipoproteins during fat and cholesterol absorption in the dog. J. biol. Chem. 1958, 233, 838.

26. Bang, I. Über Lipämie. III. Biochem. Z. 1918, 91, 111.

27. Hiller, A., Linder, G. C., Lundsgaard, C., and Van Slyke, D. D. Fat metabolism in nephritis. J. exp. Med. 1924, 39, 931.

28. Gage, S. H., and Fish, P. A. Fat digestion, absorption, and assimilation in man and animals as determined by the dark-field microscope, and a fatsoluble dye. Amer. J. Anat. 1924, 34, 1.

29. Man, E. B., and Gildea, E. F. The effect of the ingestion of a large amount of fat and of a balanced meal on the blood lipids of normal man. J. biol. Chem. 1932, 99, 61.

30. Dole, V. P. The transport of non-esterified fatty acids in plasma in The Chemistry of Lipids as Related to Atherosclerosis, I. H. Page, Ed. Springfield, Illinois, Charles C Thomas, 1958, p. 189.

31. Fredrickson, D. S., McCollester, D. L., and Ono, K. The role of unesterified fatty acid transport in chylomicron metabolism. J. clin. Invest. 1958, 37, 1333. 